\title{
ARTICLE OPEN \\ State-level prevalence, health service use, and spending vary widely among Medicare beneficiaries with Parkinson disease
}

\author{
Sneha Mantri ${ }^{1,2}$, Michelle E. Fullard ${ }^{2}$, James Beck ${ }^{3}$ and Allison W. Willis ${ }^{2,4,5}$
}

State-level variations in disease, healthcare utilization, and spending influence healthcare planning at federal and state levels and should be examined to understand national disparities in health outcomes. This descriptive study examined state-level variations in Parkinson disease (PD) prevalence, patient characteristics, Medicare spending, out-of-pocket costs, and health service utilization using data on 27.5 million Medicare beneficiaries in the US in 2014 . We found that $45.8 \%(n=179,496)$ of Medicare beneficiaries diagnosed with PD were women; $26.1 \%(n=102,205)$ were aged $85+$. The District of Columbia, New York, Illinois, Connecticut, and Florida had the highest age-, race-, and sex-adjusted prevalence of Parkinson disease among Medicare beneficiaries in the US. Women comprised over $48.5 \%$ of PD patient populations in West Virginia, Kentucky, Mississippi, Louisiana, and Arkansas. More than $31 \%$ of the PD populations in Connecticut, Pennsylvania, Hawaii, and Rhode Island were aged 85+. PD patients who were "dualeligible" - receiving both Medicare and Medicaid benefits—also varied by state, from $<10 \%$ to $>25 \%$. Hospitalizations varied from 304 to 653 stays per 1000 PD patients and accounted for $26.5 \%$ of the 7.9 billion United States Dollars (USD) paid by the Medicare program for healthcare services delivered to our sample. A diagnosis of PD was associated with greater healthcare use and spending. This study provides initial evidence of substantial geographic variation in PD patient characteristics, health service use, and spending. Further study is necessary to inform the development of state- and federal-level health policies that are cost-efficient and support desired outcomes for PD patients.

npj Parkinson's Disease (2019)5:1 ; https://doi.org/10.1038/s41531-019-0074-8

\section{INTRODUCTION}

State-level variation in disease prevalence, ${ }^{1,2}$ health care utilization, spending/costs, ${ }^{3,4}$ healthcare quality, ${ }^{5}$ and clinical outcomes $^{6-10}$ have been observed among Medicare beneficiaries. These data have driven health care reform initiatives and influenced health care planning at federal and state levels, in attempts to normalize spending and reduce inequity in care and outcomes. In the US, health care and reimbursement are increasingly governed at the state level. For instance, Medicare ${ }^{11}$ is a federally administered program providing health insurance to individuals over the age of 65 , while Medicaid, which provides coverage to individuals below the poverty line, is funded by individual states. ${ }^{11}$ Persons covered by both programs are termed "dual-eligibles". Medicare beneficiaries who are dual-eligible and have a neurodegenerative disease, like Parkinson disease (PD), have often qualified for Medicaid due to loss of wealth from health care expenses and/or long-term care services. For dualeligible individuals over the age of 65 , Medicare remains the primary payer for office visits, hospitalizations, home health, and skilled nursing facility care; Medicaid assists with remaining costs of care.

PD is a common neurodegenerative condition marked by sociodemographic disparities in care and outcomes. ${ }^{12-14}$ However, there are limited population-level data on geographic variations in PD, and no data on how PD care and spending differ across the
US. With the increasing prevalence of PD in the US, health care needs and costs will also increase, so population-level data is needed to inform health policy and planning at the state and federal level to address these changing needs. To address these gaps in knowledge, this descriptive study examined state-level variation in PD prevalence among US Medicare beneficiaries. We also examined state-level variations in PD patient characteristics, Medicare spending, out-of-pocket health care costs, and health service utilization. These data are useful for targeting areas in which PD patients may have increased need and can be used to evaluate the effects of future changes in Medicare and Medicaid policies on persons with PD.

\section{RESULTS}

Variation in PD prevalence and characteristics

We identified 27,538,023 Medicare beneficiaries that met our inclusion criteria, of whom 392,214 had a PD diagnosis in 2014. State-level variation in the prevalence of PD per 100,000 Medicare individuals is shown in Table 1 and Fig. 1. Crude prevalence varied from $845 / 100,000$ in Minnesota to $1781 / 100,000$ in New York. The top five states-New York, Connecticut, Florida, Pennsylvania, and Rhode Island-contained $20.7 \%$ of all Medicare beneficiaries diagnosed with PD in our sample. After adjusting for baseline differences in race, age, and sex, New York, Illinois, Connecticut,

\footnotetext{
${ }^{1}$ Parkinsons Disease Research, Education, and Clinical Center (PADRECC), Philadelphia VA Medical Center, 3900 Woodland Avenue, Philadelphia, PA 19104, USA; ${ }^{2}$ Department of Neurology, University of Pennsylvania Perelman School of Medicine, Philadelphia, PA, USA; ${ }^{3}$ The Parkinson's Foundation, New York, NY, USA; ${ }^{4}$ Department of Biostatistics, Epidemiology and Informatics, University of Pennsylvania, Philadelphia, PA, USA and ${ }^{5}$ Center for Clinical Epidemiology and Biostatistics, University of Pennsylvania Perelman School of Medicine, Philadelphia, PA, USA
}

Correspondence: Michelle E. Fullard (michelle.fullard@ucdenver.edu)

These authors contributed equally: Sneha Mantri, Michelle E. Fullard

Received: 15 June 2018 Accepted: 13 December 2018

Published online: 24 January 2019 


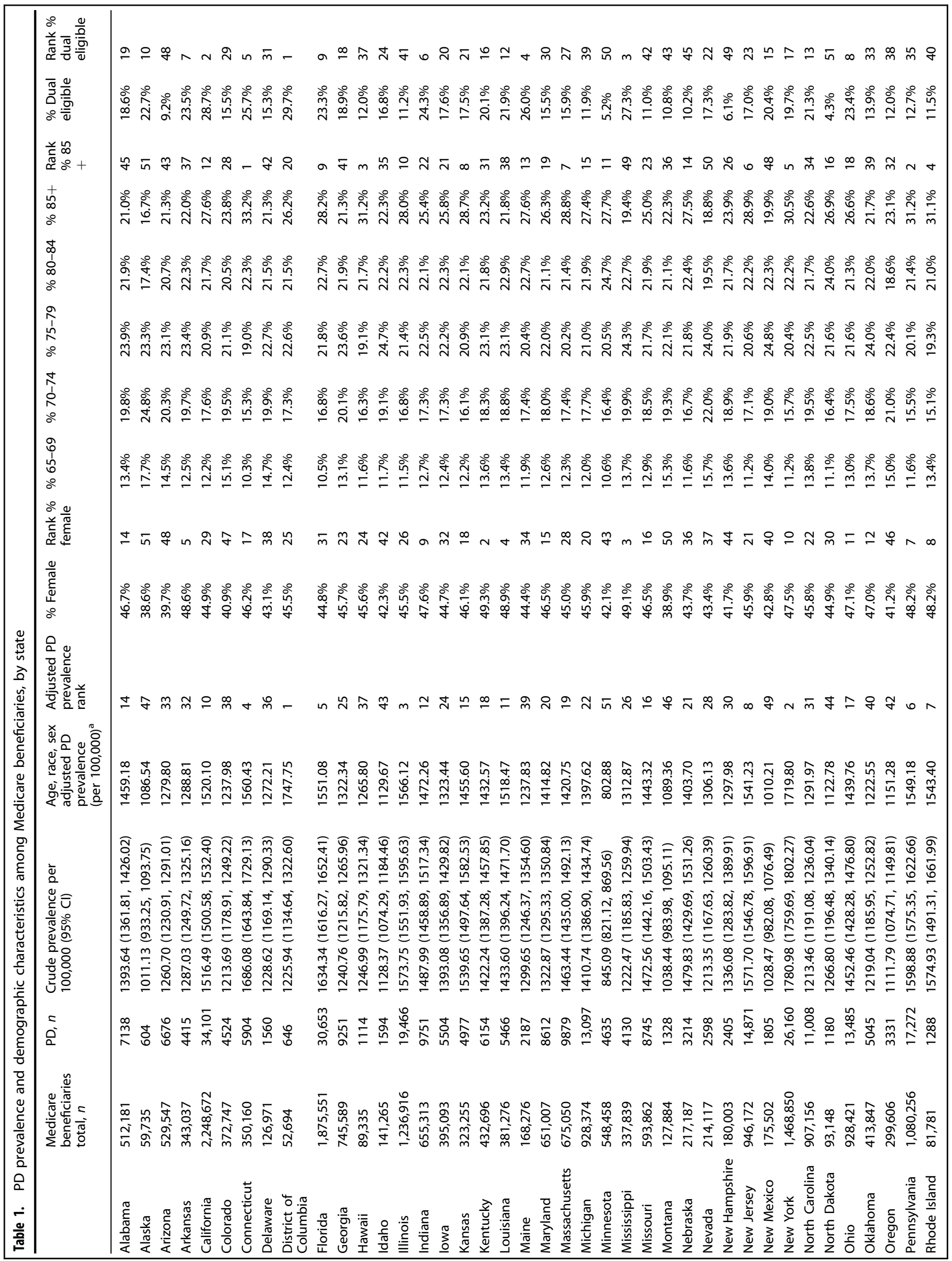


Florida, Pennsylvania, and Rhode Island remained the states with the highest prevalence.

State-level estimates of PD prevalence among adults aged 45 years and older were considerably lower, ranging from 450/ 100,000 in Alaska to $668 / 100,000$ in Florida. Prevalence estimates between the two samples were most similar in Wyoming, New Mexico, Montana, Oregon, and Idaho, all states with very low prevalence in general. In states with the greatest number of Medicare beneficiaries (New York, Texas, Connecticut, Illinois, and New Jersey), Medicare prevalence estimates were more than 2.25 times greater than estimates which included younger individuals (e-Table 1).

Nationally, 45.8\% $(n=179,496)$ of individuals diagnosed with PD in our Medicare dataset were women, and $26.1 \%(n=102,205)$ were aged 85 and above. West Virginia, Kentucky, Mississippi, Louisiana, and Arkansas had the largest proportions of PD patients who were women, over $48.5 \%$ of their state PD populations. The proportion of PD patients over the age of 85 was greatest in Connecticut (33.2\%), Pennsylvania (31.2\%), Hawaii (31.2\%), and Rhode Island (31.1\%). In contrast, less than 19\% of the PD populations in Alaska and Nevada were in the oldest age group. The percentage of individuals diagnosed with PD who were dualeligible similarly varied by state, from $<10 \%$ in North Dakota, Minnesota, New Hampshire, Arizona, Wisconsin, and Utah, to $>25 \%$ in Connecticut, Maine, Mississippi, California, and the District of Columbia (Fig. 1).

Health care utilization

In the year 2014, our Medicare PD sample had 219,049 hospitalizations (558 per 1000 PD); 37,839 readmissions (172 per 1000 hospitalizations); 3,699,767 outpatient physician office visits (9433 per 1000 PD); 34,159 hospice stays (87 per 1000 PD); 113,027 skilled nursing facility stays (288 per 1000 PD); 466,160 emergency room visits (1188 per 1000 PD), of which $39.0 \%$ resulted in hospital admission; 1,308,934 durable medical equipment events (3337 per 1000 PD); 6,676,119 laboratory tests $(17,021$ per $1000 \mathrm{PD}) ; 2,435,654$ imaging events (6210 per 1000 PD); and 4,879,538 home health visits (12,441 per 1000 PD). The portion of our sample that had prescription coverage had 16.5 million prescription events.

As shown in Table 2 and Fig. 2, Medicare beneficiaries with PD in Hawaii, Alaska, Utah, North Dakota, and Idaho had the lowest per capita number of hospitalizations (from 304 to 384 per 1000 PD). This was nearly half the hospitalization per capita rate found in New York, Michigan, Illinois, West Virginia, and Florida (624-653 hospital stays per 1000 PD). Thirty-day readmissions have become an increasingly used metric for performance evaluations and reimbursement guidelines. The readmission rate, which varied less by state, was highest in Florida (127 per 1000 hospitalizations), and greater than 115 per 1000 hospitalizations in the District of Columbia, New York, Michigan, and Arkansas. The lowest readmission rates per capita (less than 50 per 1000 hospitalizations) were found in Utah, North Dakota, South Dakota, Alaska, and Hawaii.

Approximately 7.9 billion United States Dollars (USD) were paid by the Medicare program for health care services delivered to our PD sample in 2014. The costliest services were inpatient care (2.1 billion USD), skilled nursing facility care (1.4 billion USD), hospital outpatient care (881.0 million USD), and home health (776.5 million USD). For all health care services, Medicare and out-ofpocket spending was significantly higher for beneficiaries with PD than for beneficiaries without PD (e-Table 2).

There was significant state and regional variation in per capita CMS and out of pocket costs (Fig. 3 and Table 3). The top five states for CMS spending were Nevada, Texas, Massachusetts, Florida, and New York (all greater than 22,000 USD per beneficiary with PD), almost double what was spent in South Dakota and 


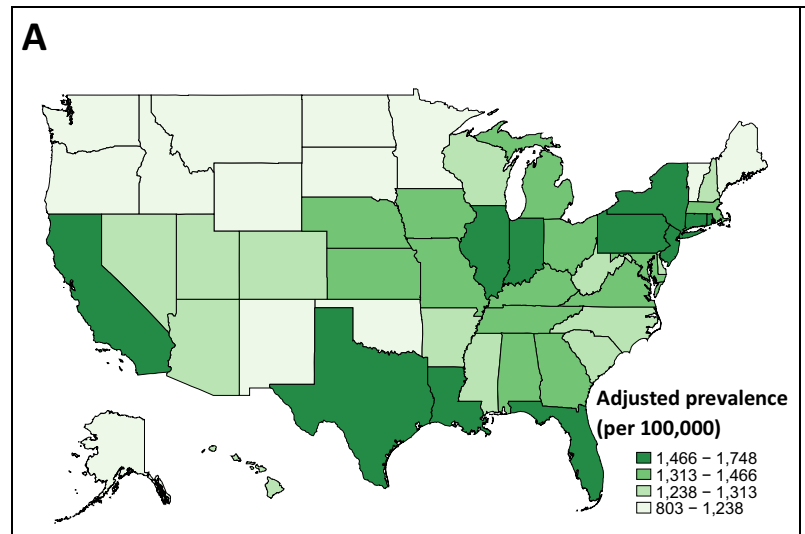

B

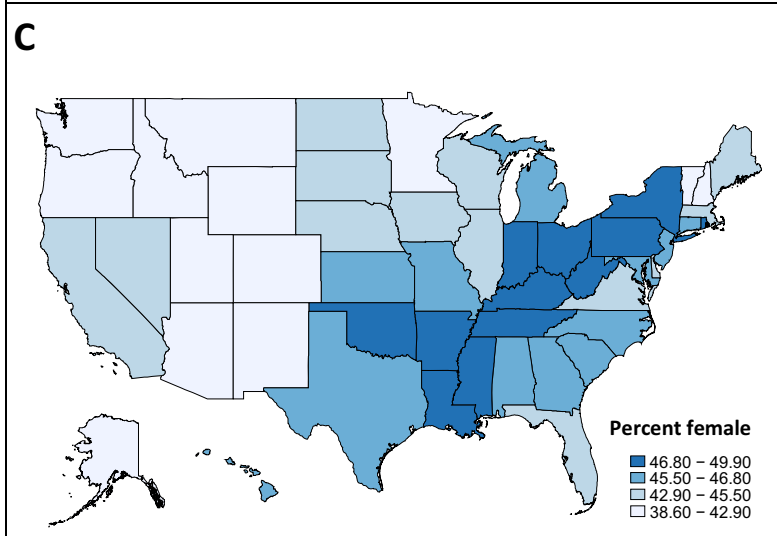

D
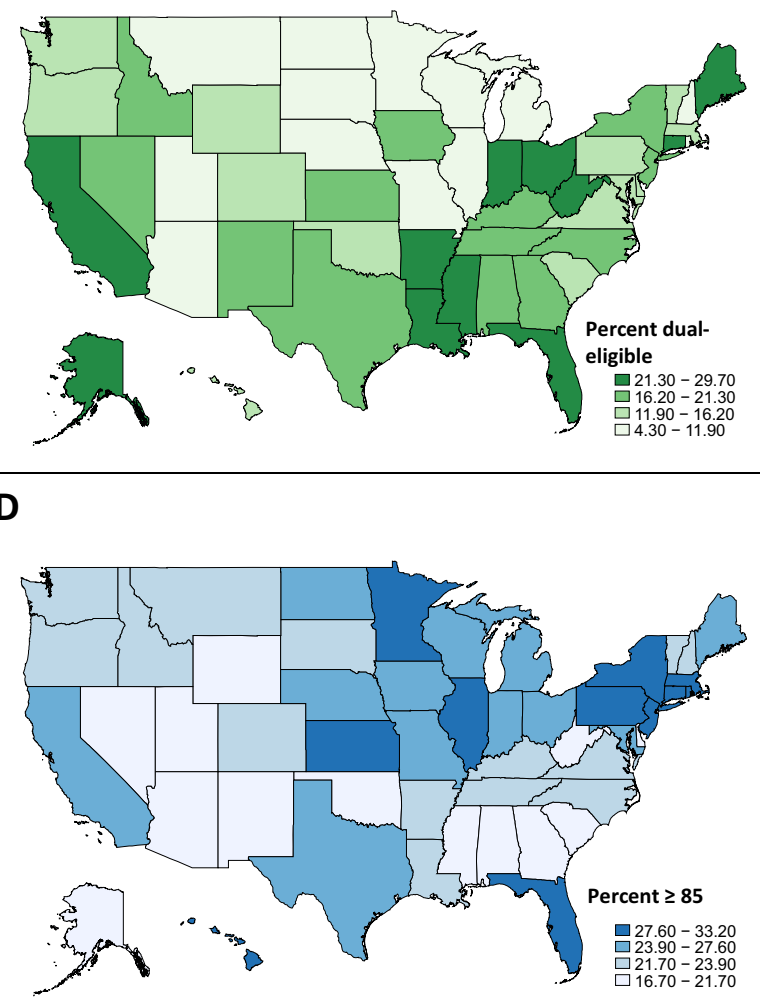

Fig. 1 Prevalence of Parkinson's disease and characteristics of individuals with PD by state. a Prevalence of Parkinson's disease (per 100,000), adjusted for age, race, and sex, among Medicare beneficiaries in 2014. b Percentage of Medicare PD population that is dual-eligible. c Percentage of Medicare PD population that is female. d Percentage of Medicare PD population aged 85 years and older. Data are shown in quartiles

Hawaii. Beneficiary responsibility is proportional to CMS spending; therefore, states in the top quartile for CMS spending were also in the top quartile for out-of-pocket costs. The highest out-of-pocket costs were in the Great Lakes, northeast, and south-central regions. The lowest costs were in the Pacific Northwest, mountain regions, and parts of the South.

\section{DISCUSSION}

In this descriptive study, we determined that among Medicare beneficiaries, there is significant state-level variation in PD prevalence, demography, dual-eligible status, and spending. States which have a higher prevalence of PD may have a larger proportion of high-risk factor patient groups, a higher concentration of providers who recognize and document PD, increased public awareness of PD symptoms, or increased health care seeking behaviors among people living in the state. Among our top PD prevalence states, Florida and New York also rank high in terms of absolute number of Medicare beneficiaries, and have large supplies of health care providers. Environmental factors, including exposure to exogenous toxicants (such as pesticides, ${ }^{15}$ heavy metals, ${ }^{16}$ or solvents ${ }^{17}$ ) vary by location and may influence our prevalence estimates by altering the risk of PD or of a PD diagnosis. There are proposed protective factors for PD, such as coffee consumption ${ }^{18,19}$ and exercise habits, ${ }^{20,21}$ but it is not clear whether these vary sufficiently across states to impact PD prevalence estimates. Finally, prevalence calculations can be impacted by differential mortality. Future research will seek to understand the geographic variation of PD in terms of differences in risk, mortality, and diagnostic accuracy.
The strongest risk factor for PD is age. ${ }^{22,23}$ Therefore, it is not surprising that PD prevalence estimates for individuals aged 45 and above were substantially lower than those estimated using a population sample aged 65 and older. These lower prevalence estimates reflect the uncommonness of PD diagnoses among individuals below the age of 60 and highlights the importance of presenting age-stratified data for PD burden estimates, particularly if that data includes very low-risk subpopulations.

The geographic variation in the proportion of dual-eligible individuals among PD is more challenging to explain. The most concerning potential contributing factors to high proportions of dual eligibles in a state are increased need for permanent nursing facility care due to suboptimal management of PD, or an increased incidence of outcomes that precipitate nursing home placement, such as cognitive impairment or falls with injury. Ease of obtaining Medicaid may also explain a portion of our findings; states with above-average percentages of dual eligible may have a higher relative income threshold for Medicaid eligibility, or formal/ informal processes in place that facilitate Medicaid receipt. While Medicaid eligibility is administered at the state level, federal subsidies are given to states to offset the costs of the program. The amount of federal support varies from state to state, as decided by state leaders. For example, the District of Columbia, California, Arkansas, Ohio, and Connecticut, which had some of the highest proportions of dual eligible PD patients, had also opted to expand Medicaid eligibility as part of the Affordable Care Act (ACA), and had done so by 2014. ACA-supported Medicaid expansion was not designed to impact older dual eligibles; however, there may be spillover effects that result in the increased pursuit of Medicaid eligibility by PD patients in these states. Other states in the top quartile for dual eligibles-Mississippi, Louisiana, 


\begin{tabular}{|c|c|c|c|c|c|c|c|c|c|c|c|c|c|c|c|}
\hline Alaska & 604 & 206 & 341 & 50 & 26 & 43 & 50 & 125 & 207 & 50 & 387 & 641 & 32 & 24.4 & 36 \\
\hline Arizona & 6676 & 2952 & 442 & 41 & 448 & 67 & 39 & 2326 & 348 & 36 & 4299 & 644 & 31 & 35.1 & 25 \\
\hline Arkansas & 4415 & 2730 & 618 & 7 & 513 & 116 & 5 & 2143 & 485 & 13 & 16,078 & 3642 & 4 & 11.8 & 48 \\
\hline California & 34,101 & 17,818 & 523 & 29 & 3224 & 95 & 21 & 15,366 & 451 & 24 & 7347 & 215 & 45 & 67.7 & 6 \\
\hline Colorado & 4524 & 1907 & 422 & 43 & 229 & 51 & 46 & 1480 & 327 & 37 & 801 & 177 & 49 & 64.9 & 8 \\
\hline Connecticut & 5904 & 3358 & 569 & 17 & 582 & 99 & 18 & 3044 & 516 & 9 & 20,459 & 3465 & 5 & 13.0 & 45 \\
\hline Georgia & 9251 & 5054 & 546 & 24 & 867 & 94 & 23 & 4195 & 453 & 23 & 4683 & 506 & 36 & 47.3 & 16 \\
\hline Hawaii & 1114 & 339 & 304 & 51 & 45 & 40 & 51 & 307 & 276 & 46 & 729 & 654 & 30 & 29.6 & 28 \\
\hline Idaho & 1594 & 612 & 384 & 47 & 84 & 53 & 45 & 383 & 240 & 48 & 2656 & 1666 & 11 & 12.6 & 47 \\
\hline Illinois & 19,466 & 12,269 & 630 & 3 & 2139 & 110 & 8 & 10,160 & 522 & 7 & 3641 & 187 & 47 & 73.6 & 3 \\
\hline Indiana & 9751 & 5418 & 556 & 21 & 869 & 89 & 26 & 4176 & 428 & 28 & 1822 & 187 & 48 & 69.6 & 4 \\
\hline lowa & 5504 & 2491 & 453 & 39 & 356 & 65 & 41 & 1601 & 291 & 42 & 4485 & 815 & 20 & 26.3 & 33 \\
\hline Kansas & 4977 & 2618 & 526 & 28 & 378 & 76 & 33 & 1751 & 352 & 35 & 5295 & 1064 & 19 & 24.9 & 35 \\
\hline Kentucky & 6154 & 3828 & 622 & 6 & 644 & 105 & 12 & 2987 & 485 & 14 & 546 & 89 & 51 & 84.5 & 1 \\
\hline Louisiana & 5466 & 3296 & 603 & 10 & 596 & 109 & 9 & 2613 & 478 & 16 & 9194 & 1682 & 10 & 22.1 & 39 \\
\hline Maine & 2187 & 1159 & 530 & 27 & 215 & 98 & 19 & 861 & 394 & 31 & 5511 & 2520 & 6 & 13.5 & 44 \\
\hline Maryland & 8612 & 4838 & 562 & 19 & 866 & 101 & 15 & 4233 & 492 & 12 & 11,750 & 1364 & 12 & 26.5 & 31 \\
\hline New Hampshire & 2405 & 1186 & 493 & 32 & 201 & 84 & 29 & 922 & 383 & 32 & 22,095 & 9187 & 1 & 4.0 & 50 \\
\hline New Jersey & 14,871 & 9014 & 606 & 9 & 1658 & 111 & 7 & 8235 & 554 & 2 & 3679 & 247 & 44 & 69.1 & 5 \\
\hline New Mexico & 1805 & 840 & 465 & 38 & 133 & 74 & 35 & 636 & 352 & 34 & 553 & 306 & 40 & 53.5 & 11 \\
\hline New York & 26,160 & 16,327 & 624 & 5 & 3129 & 120 & 3 & 14,291 & 546 & 3 & 14,039 & 537 & 34 & 50.4 & 13 \\
\hline North Carolina & 11,008 & 5374 & 488 & 34 & 851 & 77 & 31 & 4509 & 410 & 29 & 4688 & 426 & 38 & 49.0 & 14 \\
\hline North Dakota & 1180 & 446 & 378 & 48 & 52 & 44 & 48 & 222 & 188 & 51 & 844 & 715 & 27 & 20.8 & 41 \\
\hline Ohio & 13,485 & 7910 & 587 & 13 & 1406 & 104 & 13 & 6519 & 483 & 15 & 10,690 & 793 & 21 & 37.9 & 23 \\
\hline Oklahoma & 5045 & 2787 & 552 & 23 & 475 & 94 & 22 & 2250 & 446 & 25 & 6541 & 1297 & 13 & 25.6 & 34 \\
\hline Oregon & 3331 & 1324 & 397 & 45 & 192 & 58 & 42 & 963 & 289 & 43 & 917 & 275 & 42 & 51.2 & 12 \\
\hline Pennsylvania & 17,272 & 10,026 & 580 & 15 & 1685 & 98 & 20 & 8827 & 511 & 10 & 4950 & 287 & 41 & 64.1 & 9 \\
\hline Rhode Island & 1288 & 773 & 600 & 11 & 135 & 105 & 11 & 678 & 526 & 6 & 1019 & 791 & 22 & 40.0 & 21 \\
\hline South Carolina & 6371 & 3163 & 496 & 31 & 493 & 77 & 30 & 2565 & 403 & 30 & 8260 & 1296 & 14 & 23.7 & 37 \\
\hline South Dakota & 1352 & 527 & 390 & 46 & 59 & 44 & 49 & 310 & 229 & 49 & 1471 & 1088 & 18 & 17.4 & 43 \\
\hline Tennessee & 8595 & 4761 & 554 & 22 & 781 & 91 & 25 & 3959 & 461 & 21 & 970 & 113 & 50 & 80.3 & 2 \\
\hline Texas & 28,075 & 15,779 & 562 & 18 & 2562 & 91 & 24 & 12,951 & 461 & 20 & 7552 & 269 & 43 & 63.2 & 10 \\
\hline Utah & 2232 & 839 & 376 & 49 & 102 & 46 & 47 & 633 & 284 & 44 & 1231 & 552 & 33 & 34.0 & 26 \\
\hline Vermont & 1035 & 441 & 426 & 42 & 73 & 71 & 37 & 304 & 294 & 41 & 2091 & 2020 & 7 & 12.7 & 46 \\
\hline Virginia & 10,990 & 5648 & 514 & 30 & 969 & 88 & 27 & 4835 & 440 & 27 & 2333 & 212 & 46 & 67.5 & 7 \\
\hline Washington & 7424 & 2957 & 398 & 44 & 423 & 57 & 43 & 2291 & 309 & 39 & 3317 & 447 & 37 & 40.9 & 20 \\
\hline West Virginia & 2745 & 1789 & 652 & 2 & 314 & 114 & 6 & 1373 & 500 & 11 & 5515 & 2009 & 8 & 19.9 & 42 \\
\hline Wisconsin & 6960 & 3430 & 493 & 33 & 526 & 76 & 34 & 2563 & 368 & 33 & 8878 & 1276 & 16 & 22.4 & 38 \\
\hline Wyoming & 662 & 322 & 486 & 35 & 37 & 56 & 44 & 197 & 298 & 40 & 5476 & 8272 & 2 & 3.5 & 51 \\
\hline
\end{tabular}




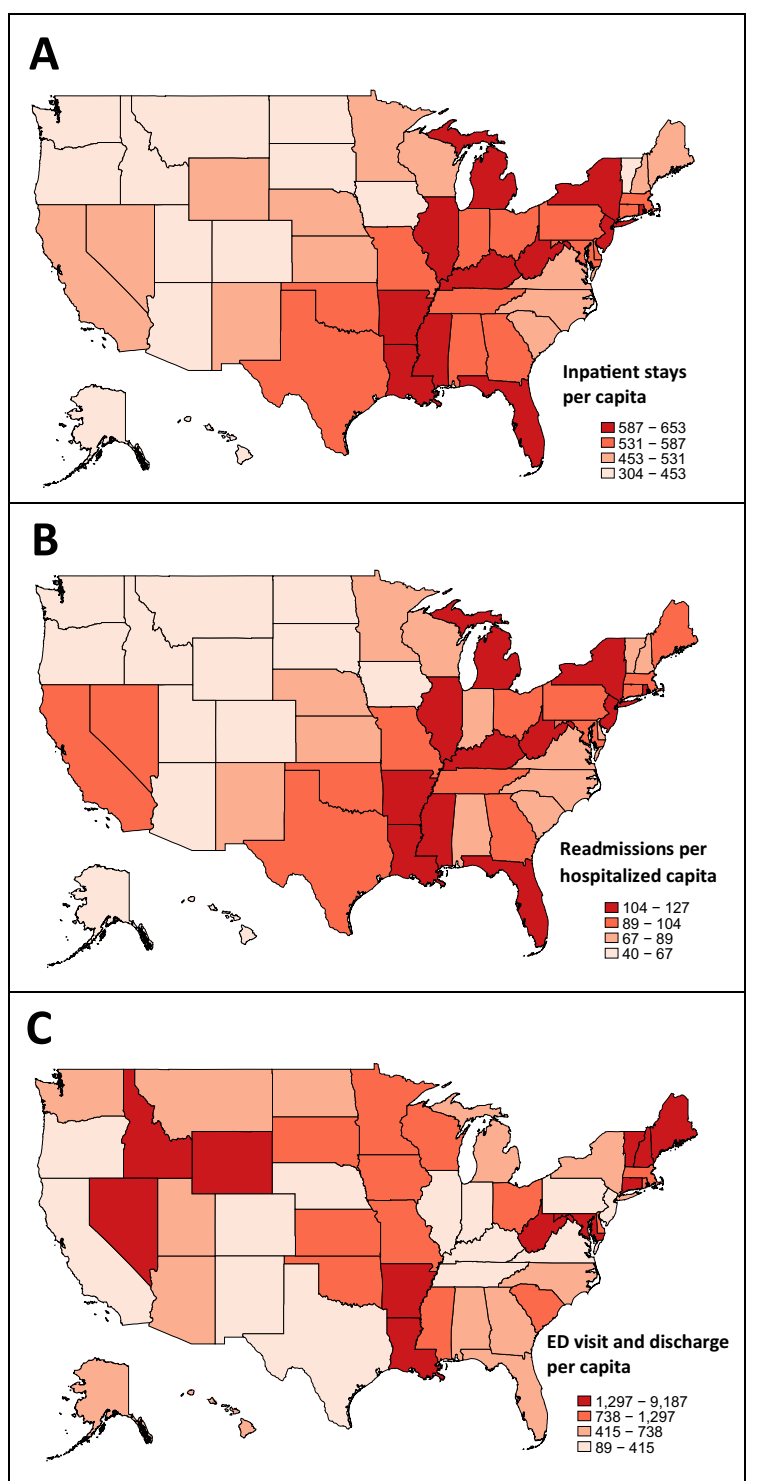

Fig. 2 ER visits and hospitalizations in the PD population by state. a Number of acute inpatient stays, per 1000 PD patients, in Medicare beneficiaries with PD in 2014. b Number of readmissions, per 10,000 hospitalized PD patients, in Medicare beneficiaries with PD in 2014. c Number of ED visits with discharge, per 1000 PD patients, in Medicare beneficiaries with PD in 2014. Data are shown in quartiles

and Indiana-also have the highest proportions of individuals living at or below the poverty line. ${ }^{24}$ The interplay between the need for long-term care services, subsidies, income, and Medicaid eligibility is complex. Future studies will determine how PD patients may be uniquely impacted by state and federal level Medicare policies.

We noted in our sample that women comprised close to half of the PD population in some states. Other epidemiologic studies have shown that the incidence and prevalence of PD among women is lower than that of men. ${ }^{25,26}$ It is important to point out the distinction between disease prevalence and proportion of a disease population with a specific characteristic. When CMS datasets are used to calculate PD prevalence and incidence, the expected male:female ratio of 1.5:1 is observed. ${ }^{27}$ In this study, we focused our sex data calculations on the PD sample alone and report the proportion of Medicare beneficiaries diagnosed with PD that is female, not the prevalence of PD among female Medicare beneficiaries. Female Medicare beneficiaries outnumber male

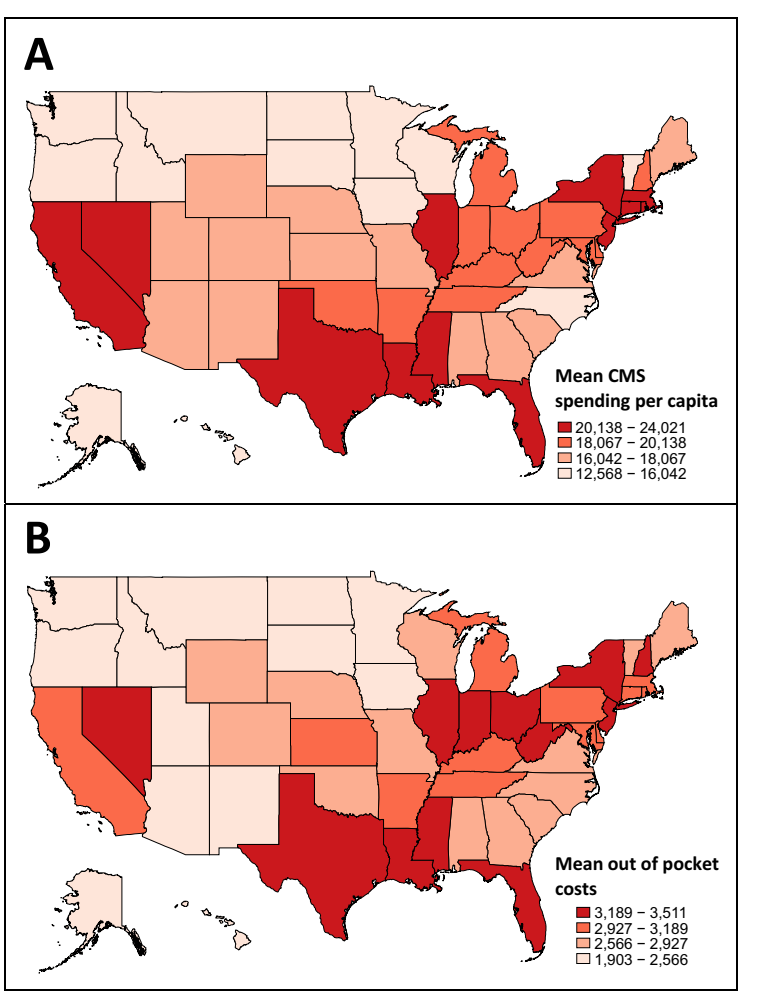

Fig. 3 Medicare spending and out of pocket costs by state. a Mean CMS spending per capita for Medicare beneficiaries with PD, 2014. b Out of pocket costs per Medicare beneficiary with PD, 2014. Data are shown in quartiles

beneficiaries, and women have a greater life expectancy, both in the general population ${ }^{28}$ and among individuals with PD. ${ }^{29}$ Thus, our finding that nearly half of Medicare beneficiaries with PD are female is expected. Although women diagnosed with PD are a sizable portion of the PD population, they are highly underrepresented in PD research and clinical trials. Recent data suggests that current payer models and care patterns do not meet the needs of women with PD, who have less access to specialized care and greater unreimbursed care needs. ${ }^{13,30}$ Improving PD outcomes will require increased attention to women with PD, from both research and clinical perspectives, especially given that almost half of the Medicare PD population is made up of women.

The concept of comparing Medicare utilization and cost by state was pioneered by the Dartmouth Atlas of Health Care, and their data showing significant variation has led to efforts to improve health systems across the US. ${ }^{31-33}$ In the general population, such variation is suggested to be due to regional differences in health care seeking behavior, increased need due to greater comorbid disease burden or social determinants of health, or increased availability of providers. ${ }^{2,34}$ Hospitalization for PD specialist care, such as deep brain stimulator (DBS) implantation, could contribute to our observed differences, particularly in states with multiple academic centers, however previous research has demonstrated that DBS use among Medicare beneficiaries diagnosed with PD is very low. ${ }^{14}$ In particular, our data on hospitalizations and readmissions do not follow a pattern consistent with provider availability. Excess hospitalizations and readmissions of PD patients occurred in Southern and Midwest states, which are known to have health provider shortages. Future studies will examine the nature of hospitalizations of PD patients and determine the extent to which they are PD related or avoidable (i.e., due to medication misadventure, ambulatory care sensitive condition). 


\begin{tabular}{|c|c|c|c|c|c|c|}
\hline \multirow[t]{3}{*}{ State name } & \multicolumn{6}{|c|}{ Spending by payer in 2014 US Dollars } \\
\hline & \multicolumn{3}{|l|}{ CMS } & \multicolumn{3}{|c|}{$\begin{array}{l}\text { Beneficiary/out of } \\
\text { pocket }\end{array}$} \\
\hline & Mean & Std dev. & Rank & Mean & Std dev. & Rank \\
\hline Alabama & 17,623 & 23,830 & 29 & 2705 & 3814 & 34 \\
\hline Alaska & 12,954 & 22,376 & 49 & 2034 & 2745 & 50 \\
\hline Arizona & 17,447 & 26,231 & 31 & 2433 & 3337 & 42 \\
\hline Arkansas & 18,707 & 26,877 & 23 & 3025 & 4474 & 23 \\
\hline California & 22,774 & 38,562 & 8 & 3071 & 4978 & 21 \\
\hline Colorado & 16,722 & 25,346 & 35 & 2613 & 3944 & 36 \\
\hline Connecticut & 22,002 & 31,726 & 9 & 3178 & 4523 & 14 \\
\hline Delaware & 19,495 & 29,910 & 21 & 2956 & 4061 & 24 \\
\hline District of Columbia & 19,703 & 36,094 & 20 & 3097 & 4674 & 19 \\
\hline Florida & 23,193 & 29,918 & 4 & 3509 & 4724 & 2 \\
\hline Georgia & 18,067 & 27,984 & 26 & 2873 & 4363 & 28 \\
\hline Hawaii & 12,568 & 22,087 & 51 & 1903 & 2896 & 51 \\
\hline Idaho & 14,839 & 21,867 & 44 & 2369 & 3420 & 47 \\
\hline Illinois & 21,315 & 30,363 & 11 & 3458 & 4872 & 4 \\
\hline Indiana & 19,867 & 28,425 & 15 & 3472 & 4913 & 3 \\
\hline lowa & 14,262 & 21,739 & 45 & 2566 & 3490 & 39 \\
\hline Kansas & 17,775 & 24,855 & 27 & 2951 & 4052 & 25 \\
\hline Kentucky & 18,576 & 26,232 & 24 & 3189 & 4524 & 13 \\
\hline Louisiana & 22,805 & 31,423 & 7 & 3511 & 5223 & 1 \\
\hline Maine & 17,657 & 25,555 & 28 & 2814 & 3650 & 30 \\
\hline Maryland & 19,826 & 30,968 & 16 & 3079 & 4399 & 20 \\
\hline Massachusetts & 23,323 & 33,708 & 3 & 3130 & 4570 & 17 \\
\hline Michigan & 20,138 & 28,494 & 13 & 3125 & 4355 & 18 \\
\hline Minnesota & 16,042 & 24,007 & 39 & 2415 & 3362 & 44 \\
\hline Mississippi & 20,522 & 29,278 & 12 & 3295 & 5023 & 9 \\
\hline Missouri & 17,588 & 24,837 & 30 & 2927 & 3939 & 26 \\
\hline Montana & 14,261 & 22,294 & 46 & 2418 & 3136 & 43 \\
\hline Nebraska & 16,221 & 24,359 & 38 & 2925 & 4010 & 27 \\
\hline Nevada & 24,021 & 38,435 & 1 & 3202 & 5092 & 12 \\
\hline New Hampshire & 20,000 & 30,846 & 14 & 3221 & 4782 & 10 \\
\hline New Jersey & 22,884 & 33,858 & 6 & 3430 & 4881 & 5 \\
\hline New Mexico & 17,010 & 24,964 & 34 & 2515 & 3916 & 40 \\
\hline New York & 22,960 & 36,240 & 5 & 3358 & 4842 & 6 \\
\hline North Carolina & 15,983 & 22,996 & 40 & 2742 & 3979 & 32 \\
\hline North Dakota & 13,380 & 25,279 & 48 & 2409 & 3331 & 45 \\
\hline Ohio & 19,765 & 28,555 & 19 & 3210 & 4594 & 11 \\
\hline Oklahoma & 19,788 & 28,698 & 18 & 2746 & 4373 & 31 \\
\hline Oregon & 13,696 & 21,428 & 47 & 2072 & 2859 & 49 \\
\hline Pennsylvania & 19,816 & 28,253 & 17 & 3151 & 4368 & 16 \\
\hline Rhode Island & 21,870 & 31,332 & 10 & 3154 & 4596 & 15 \\
\hline South Carolina & 17,240 & 25,346 & 33 & 2715 & 4182 & 33 \\
\hline South Dakota & 12,932 & 20,101 & 50 & 2407 & 3347 & 46 \\
\hline Tennessee & 18,102 & 25,362 & 25 & 3049 & 4456 & 22 \\
\hline Texas & 23,512 & 32,617 & 2 & 3340 & 5030 & 7 \\
\hline Utah & 16,691 & 25,062 & 36 & 2326 & 3475 & 48 \\
\hline Vermont & 15,855 & 25,053 & 42 & 2588 & 3536 & 38 \\
\hline Virginia & 16,682 & 25,574 & 37 & 2691 & 3859 & 35 \\
\hline Washington & 15,320 & 25,069 & 43 & 2437 & 3712 & 41 \\
\hline West Virginia & 19,440 & 28,263 & 22 & 3299 & 4725 & 8 \\
\hline
\end{tabular}

\begin{tabular}{|c|c|c|c|c|c|c|}
\hline \multirow[t]{3}{*}{ State name } & \multicolumn{6}{|c|}{ Spending by payer in 2014 US Dollars } \\
\hline & \multicolumn{3}{|l|}{ CMS } & \multicolumn{3}{|c|}{$\begin{array}{l}\text { Beneficiary/out of } \\
\text { pocket }\end{array}$} \\
\hline & Mean & Std dev. & Rank & Mean & Std dev. & Rank \\
\hline Wisconsin & 15,919 & 26,427 & 41 & 2613 & 3768 & 37 \\
\hline Wyoming & 17,407 & 26,752 & 32 & 2865 & 4116 & 29 \\
\hline
\end{tabular}

Not surprisingly, we found that beneficiaries with PD have increased health care utilization and spending compared to those without PD, which is consistent with prior, smaller studies performed in the US. ${ }^{35,36}$ This was true across all sectors of care (inpatient, outpatient, skilled nursing, and ancillary services), and is in line with other data demonstrating that PD, its complications, and the shift away from comorbid disease care and prevention that occurs after a PD diagnosis drive health care spending and utilization among these individuals. ${ }^{12,37,38}$ On average, 20,142 Medicare dollars were spent per beneficiary with PD, with the lowest spent in Hawaii (12,568 USD per PD beneficiary) and the highest in Nevada (24,021 USD per PD beneficiary). Comparison of cost with other countries is difficult due to differing methodologies, inclusion of direct and indirect costs, and usually much smaller study populations, however, a comprehensive review on the subject has been done. ${ }^{39}$ PD costs in the US are most similar to Germany, ${ }^{40}$ the $\mathrm{UK}^{41}$ and Australia ${ }^{42}$ and higher than those in Sweden, Finland, Austria, Italy, Portugal, Russia, and the Czech Republic. ${ }^{43,44}$ Hospitalizations were the main driver of cost in many of these studies.

By examining state-level variation in out-of-pocket and CMS payments, we identified regions of high and low spending, which are not consistently the regions with the highest PD prevalence. Variation in spending patterns may be due to local practice patterns, ${ }^{7,45}$ migration patterns of higher-risk individuals, ${ }^{2,46}$ or both. The proportion of state expenditures related to PD care will rise as PD prevalence increases; research to understand these variations is necessary to develop policies aimed at reducing state health care expenditures associated with undesired patient or clinical outcomes. ${ }^{47}$ In particular, economic burden data that includes the younger PD population is needed, not only to provide a complete picture of the economic burden of PD, but also because younger individuals with PD are less likely to have comorbid conditions. Thus, in this age group, medical expenditures may more directly reflect PD care costs alone.

Our study provides a comprehensive assessment of state-level variation in PD prevalence and spending patterns among the Medicare population. Nevertheless, some important limitations should be noted. We relied on administrative claims data from a single year, which may not be representative of broader secular trends in PD care. Medicare administrative claims data have been shown to be both accurate and valid ${ }^{48}$ and are commonly used in studies of spending, enabling comparison to other chronic diseases. Medicare data obtained for research purposes has been subject to a strict quality assurance process. Nevertheless, unrecognized errors in coding or reporting may occur and may be non-random. Lastly, we cannot determine the extent to which spending differences were due to hyperlocal market forces, patient factors, or physician preference. Prior studies suggest that all three factors impact the cost of care. ${ }^{46}$ More study is needed to identify the major drivers for health care spending for individuals with PD. Despite these limitations, our study provides initial evidence that there is substantial geographic variation in health service use and spending for PD. Understanding the drivers of health care costs and needs for individuals with PD is necessary to guide state- and federal-level health policies that support cost efficiency and whole 
person outcomes for PD patients. Our data are important from a population health and policy perspective, but can also provide meaningful information to clinicians, as knowing the burden of Parkinson's disease in one's state is important for physician leaders, and hospital and medical school administrators to plan for and advocate for adequate provider supplies.

\section{METHODS}

This study was approved by the Institutional Review Board of the University of Pennsylvania Perelman School of Medicine. A waiver for informed consent was granted.

\section{Data sources}

The data sources for this study were the Medicare Beneficiary Summary File, which contains demographic, geographic, and detailed cost and health care utilization data on every Medicare beneficiary in the US, and Medicare Carrier Files, which contain ICD-9 and procedure codes for diagnoses made by CMS providers (e.g., physicians) in the inpatient and outpatient settings. The study population consisted of individuals aged 65 and above living in the 50 United States and the District of Columbia, who were continuously enrolled in Medicare parts $A$ (which pays for inpatient care) and B (which pays outpatient setting care and provider services) during 2014. We excluded individuals who were enrolled in Health Maintenance Organizations or Medicare Advantage programs, as complete claims and health care use data may not be available for these individuals. We queried the Carrier Files for the ICD-9 codes "332" (Parkinson disease) and "332.0" (paralysis agitans), to identify qualifying Medicare beneficiaries with an active PD diagnosis in the year 2014. Beneficiaries were excluded if they also had diagnostic claims for secondary/drug-induced parkinsonism ("332.1") or other degenerative disease of the basal ganglia/atypical Parkinson syndromes ("333.0") since these diseases have a distinct pathophysiology and clinical course.

\section{State-level PD prevalence}

Residence was assigned to one of the 50 states or to the District of Columbia (hereafter referred to simply as "state(s)") based on the beneficiary mailing address. Crude PD prevalence estimates were calculated by dividing the number of Medicare beneficiaries diagnosed with PD by the total number of Medicare beneficiaries in each state, along with $95 \%$ confidence intervals. We also calculated the proportion of PD cases in each state that was (1) aged 85+; (2) female; and (3) dual-eligible. $\mathrm{PD}$ is more frequently diagnosed in individuals who are identified as White and male, and PD risk increases with age. Therefore, we also calculated the age-, race-, and sex-adjusted prevalence of PD in each state, using the direct method of standardization and the total Medicare beneficiary population as the standard population.

We have recently used Medicare claims plus data from five other epidemiological studies to produce meta-estimates of the prevalence of PD in North America. ${ }^{49,50}$ These pooled data were used to produce statelevel PD prevalence estimates for individuals aged 45 and above, standardized to the 2010 US census population, which we present in comparison to Medicare data-derived prevalence estimates.

For Medicare beneficiaries with and without PD, we extracted data on healthcare utilization (such as the number of emergency room visits, outpatient clinical visits, and inpatient hospitalizations), and the number and refills of covered prescriptions (available for beneficiaries receiving Medicare prescription benefits). Using reimbursement data, we calculated the mean out-of-pocket and CMS cost per individual in each state. Statelevel rank order lists for PD prevalence (adjusted for age, race, and sex using direct standardization), PD demographic and eligibility characteristics, PD healthcare utilization and costs were produced. Student's $t$-test with equal variances and Bonferroni correction for multiple comparisons was used to compare direct costs and health service utilization for individuals with and without PD. Choropleth maps for state-level differences in PD population characteristics and cost were produced. Statistical analyses and mapping were performed using Stata/SE version 13.1 (StataCorp LP, College Station, TX, USA).

\section{Reporting summary}

Further information on experimental design is available in the Nature Research Reporting Summary linked to this article.
Code availability

Analytic code can be made available from the corresponding author upon request.

\section{DATA AVAILABILITY}

The data that support the findings of this study are available through ResDAC's CMS Data Request Center and are not publicly available. Due to CMS policy, the authors are unable to provide the data that was used in this study.

\section{ACKNOWLEDGEMENTS}

This study was supported by the National Institutes of Health (R01NS099129) and the Parkinson's Foundation.

\section{AUTHOR CONTRIBUTIONS}

Sneha Mantri and Michelle Fullard performed data analysis, primary writing, and revision of the manuscript. James Beck provided data used in the study and critically revised the manuscript. Allison Willis provided data, performed primary statistical analysis, as well as writing and critical revision of the manuscript. Dr. Willis is the guarantor.

\section{ADDITIONAL INFORMATION}

Supplementary information accompanies the paper on the npj Parkinson's Disease website (https://doi.org/10.1038/s41531-019-0074-8).

Competing interests: The authors declare no competing interests.

Publisher's note: Springer Nature remains neutral with regard to jurisdictional claims in published maps and institutional affiliations.

\section{REFERENCES}

1. Koller, D. \& Bynum, J. P. W. Dementia in the USA: state variation in prevalence. J. Public Health 37, 597-604 (2014).

2. Lochner, K., Goodman, R., Posner, S. \& Parekh, A. Multiple chronic conditions among Medicare beneficiaries: State-level variations in prevalence, utilization, and cost, 2011. Medicare Medicaid Res. Rev. 3, E1-E19 (2013).

3. Sisko, A. \& Cuckler, G. Modeling per capita state health expenditure variation: state-level characteristics matter. Medicare Medicaid Res. Rev. 3, 1-24 (2013).

4. Kronick, R. \& Gilmer, T. P. Medicare and medicaid spending variations are strongly linked within hospital regions but not at overall state level. Health Aff. 31, 948-955 (2012).

5. Finkelstein, E. A., Fiebelkorn, I. C. \& Wang, G. State-level estimates of annual medical expenditures attributable to obesity. Obes. Res. 12, 18-24 (2004).

6. Thompson, M. P. et al. Regional variation in 30-day ischemic stroke outcomes for Medicare beneficiaries treated in get with the guidelines-stroke hospitals. Circ. Cardiovasc. Qual. Outcomes 10, e003604 (2017).

7. Rosenkrantz, A. B., Hughes, D. R. \& Duszak, R. State variation in medical imaging: despite great variation, the Medicare spending decline continues. Am. J. Roentgenol. 205, 817-821 (2015).

8. Wetmore, J. B. et al. Race, ethnicity, and state-by-state geographic variation in hemorrhagic stroke in dialysis patients. Clin. J. Am. Soc. Nephrol. 9, 756-763 (2014).

9. Jin, E. \& Agrawal, R. State-by-state variation in the number of children and young adults in nursing homes, 2005-2012. Matern. Child Health J. 21, 2149-2152 (2017).

10. Mehrotra, A. et al. Rapid growth in mental health telemedicine use among rural Medicare beneficiaries, wide variation across states. Health Aff. 36, 909-917 (2017).

11. Berkowitz, E. Medicare and Medicaid: the past as prologue. Health Care Financ. Rev. 27, 11-23 (2005).

12. Fullard, M. E. et al. Sex disparities in health and health care utilization after Parkinson diagnosis: rethinking PD associated disability. Parkinsonism Relat. Disord. 48, 45-50 (2017).

13. Dahodwala, N. et al. Sex disparities in access to caregiving in Parkinson disease. Neurology 90, e48-e54 (2018).

14. Willis, A. W. et al. Disparities in deep brain stimulation surgery among insured elders with Parkinson disease. Neurology 82, 163-171 (2014).

15. Wang, A. et al. Parkinson's disease risk from ambient exposure to pesticides. Eur. J. Epidemiol. 26, 547-555 (2011). 
16. Willis, A. W. et al. Metal emissions and urban incident Parkinson Disease: a community health study of Medicare beneficiaries by using geographic information systems. Am. J. Epidemiol. 172, 1357-1363 (2010).

17. Goldman, S. M. et al. Solvent exposures and Parkinson disease risk in twins. Ann. Neurol. 71, 776-784 (2012).

18. Ascherio, A. et al. Prospective study of caffeine consumption and risk of Parkinson's disease in men and women. Ann. Neurol. 50, 56-63 (2001).

19. Costa, J., Lunet, N., Santos, C., Santos, J. \& Vaz-Carneiro, A. Caffeine exposure and the risk of Parkinson's disease: a systematic review and meta-analysis of observational studiess. J. Alzheimer's Dis. 20, S221-S238 (2010).

20. Sunwoo, M. K. et al. Premorbid exercise engagement and motor reserve in Parkinson's disease. Parkinsonism Relat. Disord. 34, 49-53 (2017).

21. Rafferty, M. R. et al. Regular exercise, quality of life, and mobility in Parkinson's disease: a longitudinal analysis of National Parkinson Foundation quality improvement initiative data. J. Parkinsons Dis. 7, 193-202 (2017).

22. Pagano, G., Ferrara, N., Brooks, D. J. \& Pavese, N. Age at onset and Parkinson disease phenotype. Neurology 86, 1400-1407 (2016).

23. Noyce, A. J. et al. PREDICT-PD: identifying risk of Parkinson's disease in the community: methods and baseline results. J. Neurol. Neurosurg. Psychiatry $\mathbf{8 5}$ 31-37 (2014)

24. Work, C. T. O. Selected economic characteristics 2010-2014. American Community Survey 5-Year Estimates, Vol. 2, 3-7 (2017).

25. Alves, G. et al. Incidence of Parkinson's disease in Norway: the Norwegian ParkWest study. J. Neurol. Neurosurg. Psychiatry 80, 851-857 (2009).

26. Baldereschi, M. et al. Parkinson's disease and parkinsonism in a longitudinal study. Neurology 55, 1358 (2000).

27. Willis, A. W., Evanoff, B. A., Lian, M., Criswell, S. R. \& Racette, B. A. Geographic and ethnic variation in Parkinson disease: a population-based study of US Medicare beneficiaries. Neuroepidemiology 34, 143-151 (2010).

28. Xu, J., Kochanek, K. D., Murphy, S. L. \& Tejada-Vera, B. Deaths: final data for 2007. Natl. Vital Stat. Rep. 58, 1-135 (2010).

29. De Lau, L. M. L., Verbaan, D., Marinus, J. \& van Hilten, J. J. Survival in Parkinson's disease. Relation with motor and non-motor features. Parkinsonism Relat. Disord. 20, 613-616 (2014)

30. Willis, A. W., Schootman, M., Evanoff, B. A., Perlmutter, J. S. \& Racette, B. A Neurologist care in Parkinson disease: a utilization, outcomes, and survival study. Neurology 77, 851-857 (2011).

31. Fisher, E. S. et al. The implications of regional variations in Medicare spending. Part 1: the content, quality, and accessibility of care. Ann. Intern. Med. 138 273-287 (2003)

32. Fisher, E. S. et al. The implications of regional variations in Medicare spending Part 2: health outcomes and satisfaction with care. Ann. Intern. Med. 138, 288-298 (2003).

33. Wennberg, J. E. et al. Use of hospitals, physician visits, and hospice care during last six months of life among cohorts loyal to highly respected hospitals in the United States. BMJ 328, 607 (2004).

34. Holt, J. B., Zhang, X., Presley-Cantrell, L. \& Croft, J. B. Geographic disparities in chronic obstructive pulmonary disease (COPD) hospitalization among Medicare beneficiaries in the United States. Int. J. COPD 6, 321-328 (2011).

35. Huse, D. M. et al. Burden of illness in Parkinson's disease. Mov. Disord. 20, 1449-1454 (2005).
36. Noyes, K., Liu, H., Li, Y., Holloway, R. \& Dick, A. W. Economic burden associated with Parkinson's disease on elderly Medicare beneficiaries. Mov. Disord. 21 362-372 (2006)

37. Merola, A. et al. Orthostatic hypotension in Parkinson disease: impact on health care utilization. Parkinsonism Relat. Disord. 47, 45-49 (2017).

38. Willis, A. W. et al. Predictors of survival in patients with Parkinson disease. Arch Neurol. 69, 601-607 (2012)

39. Bovolenta, T. M. et al. Systematic review and critical analysis of cost studies associated with Parkinson's disease. Parkinson's Dis. 2017, 3410946 (2017).

40. Winter, Y. et al. Longitudinal study of the socioeconomic burden of Parkinson's disease in Germany. Eur. J. Neurol. 17, 1156-1163 (2010).

41. McCrone, P., Allcock, L. M. \& Burn, D. J. Predicting the cost of Parkinson's disease. Mov. Disord. 22, 804-812 (2007).

42. Mudiyanselage, S. B. et al. Cost of living with Parkinson's disease over 12 months in Australia: a prospective cohort study. Parkinson's Dis. 2017, 5932675 (2017)

43. Reese, J. P. et al. Morbus Parkinson: Krankheitskosten einer ambulanten Patientenkohorte. Gesundheitswesen 73, 22-29 (2011).

44. Lökk, J., Borg, S., Svensson, J., Persson, U. \& Ljunggren, G. Drug and treatment costs in Parkinson's disease patients in Sweden. Acta Neurol. Scand. 125, 142-147 (2012).

45. Fullard, M. E. et al. Utilization of rehabilitation therapy services in Parkinson disease in the United States. Neurology 89, 1162-1169 (2017).

46. Finkelstein, A., Gentzkow, M. \& Williams, H. Sources of geographic variation in health care: evidence from patient migration. Q. J. Econ. 131, 1681-1726 (2016).

47. Pringsheim, T., Jette, N., Frolkis, A. \& Steeves, T. D. L. The prevalence of Parkinson's disease: a systematic review and meta-analysis. Mov. Disord. 29, 1583-1590 (2014).

48. Edmonds, M. \& Sloan, F. A. Geographic Adjustment in Medicare Payment: Phase I: Improving Accuracy. (National Academies Press, Washington, US, 2011).

49. Beck, J. et al. Improving estimates of Parkinson's disease prevalence and incidence in the USA. Mov. Disord. 29, 1475 (2014).

50. Marras, C. et al. Prevalence of Parkinson's disease across North America. $n p j$ Parkinsons Dis. 4, 21 (2018).

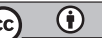

Open Access This article is licensed under a Creative Commons Attribution 4.0 International License, which permits use, sharing, adaptation, distribution and reproduction in any medium or format, as long as you give appropriate credit to the original author(s) and the source, provide a link to the Creative Commons license, and indicate if changes were made. The images or other third party material in this article are included in the article's Creative Commons license, unless indicated otherwise in a credit line to the material. If material is not included in the article's Creative Commons license and your intended use is not permitted by statutory regulation or exceeds the permitted use, you will need to obtain permission directly from the copyright holder. To view a copy of this license, visit http://creativecommons. org/licenses/by/4.0/.

C) The Author(s) 2019 